\title{
Utilização de Carneiros de Raças de Corte para Obtenção de Cordeiros Precoces para Abate em Plantéis Produtores de Lã ${ }^{1}$
}

\author{
Eduardo Antonio da Cunha ${ }^{2}$, Luiz Eduardo dos Santos ${ }^{3}$, Mauro Sartori Bueno ${ }^{3}$, Domingos \\ Sanchez Roda ${ }^{2}$, Frederico Fontoura Leinz ${ }^{4}$, Carlos Frederico de Carvalho Rodrigues ${ }^{4}$
}

\begin{abstract}
RESUMO - Sessenta e nove cordeiros filhos de ovelhas das raças Ideal ou Corriedale cobertas com machos das raças Suffolk, Ile de France, ou da mesma raça materna, foram usados para avaliar o seu desempenho e as características de carcaça. Os animais permaneceram em pastagem até o desmame (60 dias), foram confinados por 90 dias e alimentados com ração à base de silagem de milho e concentrado. Foi usado delineamento completamente casualizado em esquema fatorial. O uso de machos de corte sobre fêmeas lanígeras não causou efeito sobre o peso ao nascer e ao desmame das crias, porém aumentou o peso e a compacidade das carcaças, sem alterar as proporções de traseiro e costilhar. A espessura de gordura subcutânea não foi influenciada pelo genótipo, apresentando-se maior para fêmeas. A área de olho de lombo não apresentou diferença entre genótipos. As medidas de carcaça mostraram diferença entre genótipos, sendo as do cruzamento com Suffolk mais compridas, seguidas pelos mestiços de Ile de France.
\end{abstract}

Palavras-chave: carcaça, cordeiros, raças de corte, rendimento

\section{Use of Meat Sheep Sire Breed on Fine Wool Ewe Flocks to Produce Fast-growing Lambs for Slaughter}

\begin{abstract}
Sixty-nine lambs from the crossbreeding Corriedale or Polwarth ewes with Suffolk, Ile de France rams or from the same ewe breed were used to evaluate their performance and carcass characteristics. Lambs were maintained under grazing until weaning time (60 days), then were confined for 90 days and fed corn silage and concentrate based diet. A completely randomized design in a factorial arrangement was used. The use of meat type rams on fine wool ewes did not affect lamb birth and weaning weight, however increased the carcass weight and compacting, without effect on forequarter and ribs. Subcutaneous fat thickness was not affected by the genotype and it was greater for females. Loin eye area did not show difference between genotypes. Carcass measurements showed differences between genotypes, being the ones from Suffolk mating the longest, followed by the crossbred from Ile de France.
\end{abstract}

Key Words: carcass, lamb, meat sheep breed, dressing

\section{Introdução}

O consumo de carne ovina tem aumentado nos últimos anos, principalmente aquela originária de cordeiros entre a $16^{\mathrm{a}}$ e $22^{\mathrm{a}}$ semana de idade, que apresentam carne mais tenra e com maior palatabilidade. A produção de carne com essas características não é grande, pois a maior parte do plantel nacional não é especializada para a produção de carne. O maior número de ventres disponíveis para produção de cordeiros para abate é de ovelhas de aptidão lanígera, com predominância das raças Corriedale e Ideal. Esse tipo de animal, quando coberto com machos dessas mesmas raças, normalmente produz crias de baixo peso ao nascer e ao desmame (RODA et al. 1984), com menor potencial de ganho de peso pós-desmame, resultando em carcaças mais leves e de qualidade inferior às de animais especializados para corte.

Ovelhas lanígeras com velos fora do padrão da raça poderiam ser utilizadas para a produção de cordeiros cruzados, decorrentes de seu acasalamento com carneiros tipo carne, visando a obtenção de animais com maior peso ao desmame, maior potencial de ganho de peso em confinamento e melhores características de carcaça. Entre as raças especializadas para corte, a Suffolk e a Ile de France são as mais comuns no Estado de São Paulo, caracterizando-se pelo elevado peso adulto e excelente ganho de peso em animais jovens. RODA et al. (1993) observaram pesos ao nascer e ao desmame de 4,4 e 19,1 kg para crias Suffolk criados em pastagem.

\footnotetext{
1 Financiado pela FAPESP.

2 Pesquisador Científico do Centro de Etologia, Ambiência e Manejo do Instituto de Zootecnia, E.mail: ceam@izsp.br

3 Pesquisador Científico do Centro de Nutrição e Alimentação Animal do Instituto de Zootecnia.

${ }^{4}$ Pesquisador Científico do Núcleo de Pesquisas Zootécnicas do Sudoeste, Itapetininga, SP.
} 
A raça Ile de France, segundo observações desta equipe, produz crias pesadas ao nascer e ao desmame, com valores médios de 4,65 e 21,95 kg, respectivamente, e elevado ganho de peso pós-desmame. São animais de elevado peso adulto e, portanto, adequados ao cruzamento industrial com raças nãoespecializadas.

Aumentos significativos nos pesos ao nascer e ao desmame foram conseguidos por RODA et al. (1983), ao utilizarem carneiros Suffolk sobre fêmeas deslanadas. CASOLI et al. (1984) observaram aumentos significativos no ganho de peso diário e no peso ao abate com a utilização de machos da raça Ile de France ou Suffolk sobre fêmeas da raça Apenina, sem, contudo, observar efeito significativo no rendimento de carcaça.

GUERRA e HERNANDEZ (1992) estudaram o desenvolvimento de crias provenientes de fêmeas lanígeras (Rambouillet) cruzadas com machos de corte (Suffolk e Hampshire), em comparação com crias lanígeras puras e observaram que o peso aos 240 dias foi significativamente maior nos animais oriundos de cruzamentos que nos puros. FERNANDES (1994), trabalhando com ovinos Corriedale e cruzados Ile de France x Corriedale, concluiu que houve melhora na conformação da carcaça e na condição corporal dos cordeiros oriundos deste cruzamento, sem, contudo, modificar o rendimento de carcaça e dos seus cortes. GÜNEY (1990) também conseguiu aumentos no peso e rendimento de carcaça quente e espessura de gordura subcutânea, quando acasalou ovelhas mestiças com carneiros Ile de France.

O objetivo deste estudo foi avaliar o desempenho e as características das carcaças de cordeiros oriundos de cruzamento de carneiros de raças de corte, Suffolke Ile de France, com ovelhas de raças lanígeras, Ideal e Corriedale, em comparação com cordeiros puros destas raças lanígeras, visando o abate precoce.

\section{Material e Métodos}

O experimento foi conduzido no Instituto de Zootecnia, na sede do Núcleo de Desenvolvimento Regional de Pesquisa Zootécnica, em Itapetininga, SP, e na Unidade de Campo de Ovinos do Centro de Etologia, Ambiência e Manejo, em Nova Odessa, SP. Os cordeiros utilizados eram da parição de 1996.

Ovelhas da raça Ideal e Corriedale, com 3 anos de idade, mantidas em pastagem de coast-cross (Cynodon dactylon L. Pears) (15 ovelhas/ha), em
Itapetininga, foram acasaladas, em março de 1996, com machos Suffolk, Ile de France, ou da mesma raça. Receberam suplementação de concentrado composto de milho (48\%), farelo de algodão (17\%), soja $(24 \%)$ e trigo $(7,5 \%)$, calcário calcítico $(1,5 \%)$, sal $(1,0 \%)$ e mistura mineral $(1,0 \%)$ (Tabela 1$)$ no terço final da gestação (300 g/dia) e durante o aleitamento (400 g/dia). As crias foram desmamadas ao redor dos 60 dias (outubro de 1996), pesadas e enviadas para a Unidade de Ovinos, em Nova Odessa. Os animais foram confinados em baias coletivas de $1,5 \mathrm{x}$ 3,0 metros, com piso ripado suspenso, com sete animais por baia, durante 90 dias, sendo alimentados com silagem de milho à vontade e concentrado (idêntico ao anterior), fornecidos em duas porções diárias. O concentrado foi fornecido na quantidade de $2,5 \%$ do peso vivo do animal/dia, corrigido a cada quatorze dias.

Foram utilizadas 69 crias (31 machos e 38 fêmeas), provenientes de parto simples, representando os seguintes genótipos (tratamentos):

crias da raça Ideal (4 machos e 4 fêmeas);

crias de carneiros Suffolk com ovelhas Ideal (7 machos e 9 fêmeas);

crias de carneiros Ile de France com ovelhas Ideal (6 machos e 6 fêmeas);

crias da raça Corriedale (4 machos e 4 fêmeas); crias de carneiros Suffolk com ovelhas Corriedale (5 machos e 8 fêmeas); e

crias de carneiros Ile de France com ovelhas Corriedale (5 machos e 7 fêmeas).

Os animais foram pesados no nascimento, no desmame, a cada quatorze dias durante o período de confinamento e ao seu final, para se calcular o ganho em peso no período. O abate foi efetuado aos 150 dias de idade, sendo os animais pesados após jejum de alimento sólido por 20 horas (peso de abate). As carcaças quentes foram pesadas e, em seguida, armazenadas à temperatura de $3^{\circ} \mathrm{C}$ por 48 horas, sendo pesadas novamente (carcaça fria) e a diferença de peso denominada perdas por oreio. O rendimento de

Tabela 1 - Composição bromatológica dos alimentos (\%MS) Table 1 - Chemical composition of feeds (\%DM)

\begin{tabular}{|c|c|c|c|c|c|}
\hline Alimento & MS & PB & $\mathrm{FB}$ & $\mathrm{MO}$ & $\mathrm{Ca}$ \\
\hline Feed & $D M$ & $C P$ & $C F$ & $O M$ & \\
\hline $\begin{array}{l}\text { Silagem de milho } \\
\text { Corn silage }\end{array}$ & 27,8 & 7,41 & 28,9 & 95,7 & $0,190,16$ \\
\hline $\begin{array}{l}\text { Concentrado } \\
\text { Concentrate }\end{array}$ & 86,2 & 21,3 & 7,2 & 93,5 & $\begin{array}{ll}0,79 & 0,61\end{array}$ \\
\hline
\end{tabular}


carcaça foi calculado sobre o peso vivo ao abate (após jejum). As carcaças foram cortadas ao meio; a meia-carcaça esquerda foi pesada e mensurados o comprimento interno (distância entre a inserção do primeiro par de costelas na coluna vertebral e o sacro) e externo da carcaça (distância entre a articulação da sétima vértebra cervical e primeira torácica, até a articulação entre a última vértebra sacral com a primeira caudal), a profundidade do tórax (largura máxima do tórax, entre as extremidades distais dos processos espinhosos da terceira e quarta vértebras torácicas e a inserção da terceira e quarta costelas no esterno, medida externamente), o comprimento da perna (distância entre o trocânter maior do fêmur até a junção tarso-metatarsal) e o perímetro da perna em sua parte mais larga, conforme Figura 1. A meiacarcaça esquerda foi cortada em dianteiro (pescoço, membro anterior e cinco costelas), traseiro (perna, garupa, lombo separado do dianteiro entre a $5^{\mathrm{a}}$ e $6^{\mathrm{a}}$ costelas) e costilhar (costelas, a partir da $6^{\mathrm{a}}$, separadas do traseiro à distância de, aproximadamente, $2 \mathrm{~cm}$ da coluna vertebral, mais os músculos abdominais). A área de olho de lombo e a espessura da gordura subcutânea foram medidas no corte realizado entre a $12^{\mathrm{a}}$ e $13^{\mathrm{a}}$ costelas, utilizando-se papel vegetal quadriculado.

Os resultados de desempenho foram analisados segundo o modelo:

em que

$$
\mathrm{Y}_{\mathrm{ijk}}=m+\mathrm{t}_{\mathrm{i}}+\mathrm{s}_{\mathrm{j}}+(\mathrm{ts})_{\mathrm{ij}}+e_{\mathrm{ijk}}
$$

$\mathrm{Y}_{\mathrm{ijk}}=$ valor observado para a variável em estudo referente à repetição $\mathrm{k}$ da combinação do nível i dos genótipos com o nível j do sexo,

$\mathrm{t}_{\mathrm{i}} \quad=$ efeito do genótipo;

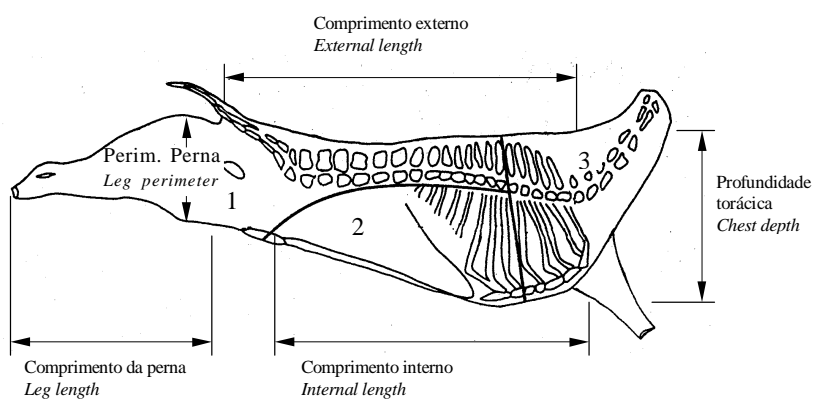

1 - Traseiro (Hindside)

2 - Costilhar (Ribs)

3 - Dianteiro (Foreside)

Figura 1 - Visualização de cortes e medidas da carcaça.

Figure 1 - Visualization of carcass cuts and measures. $\mathrm{s}_{\mathrm{j}} \quad=$ efeito do sexo do cordeiro;

$(\mathrm{ts})_{\mathrm{ij}}=$ efeito da interação do genótipo $\mathrm{X}$ sexo; $\mathrm{e}$

$e_{\mathrm{ij}}=$ erro experimental.

Para análise dos resultados de características de carcaça, foi acrescentado no modelo o efeito do peso do cordeiro ao abate, como covariável, segundo o modelo:

$$
\underset{\text { em que }}{\mathrm{Y}_{\mathrm{ijk}}=m+\mathrm{t}_{\mathrm{i}}+\mathrm{s}_{\mathrm{j}}+(\mathrm{ts})_{\mathrm{ij}}+\beta\left(\mathrm{x}_{\mathrm{ijk}}-\mathrm{x}\right)+e_{\mathrm{ijk}}}
$$

$\mathrm{Y}_{\mathrm{ijk}}=$ valor observado para a variável em estudo referente à repetição $\mathrm{k}$ da combinação do nível i dos genótipos com o nível j do sexo;

$\mathrm{t}_{\mathrm{i}} \quad=$ efeito do genótipo;

$\mathrm{s}_{\mathrm{j}} \quad=$ efeito do sexo do cordeiro;

$\beta=$ coeficiente de regressão linear;

$\mathrm{x}_{\mathrm{ijk}}=$ peso ao abate do cordeiro do genótipo i, do sexo $j$, na repetição $k$;

$(\mathrm{ts})_{\mathrm{ij}}=$ efeito da interação do genótipo x sexo; e

$e_{\mathrm{ij}}=$ erro experimental.

Foram realizadas, também, correlações entre as medidas de carcaça e peso ao abate e de carcaça dos animais.

\section{Resultados e Discussão}

Na Tabela 2, são apresentados os dados de desempenho das crias dos diferentes genótipos avaliados. O cruzamento de carneiros de corte com ovelhas de raças lanígeras não aumentou os pesos ao nascer e ao desmame das crias; todavia, o ganho de peso pré-desmame foi maior $(\mathrm{P}<0,05)$ para as crias do cruzamento Suffolk x Ideal que para as crias Corriedale e não diferiu em relação aos demais genótipos. O peso aos 150 dias dos cordeiros do cruzamento Suffolk x Ideal foi maior $(\mathrm{P}<0,01)$, somente, em relação aos dos cordeiros Ideal. O ganho de peso pós-desmame foi maior $(\mathrm{P}<0,01)$ para os cordeiros cruzados Suffolk que o dos cordeiros Ideal, não diferindo dos cordeiros Corriedale e dos cruzados Ile de France. Estes dados indicaram que a introdução de raças de corte em cruzamento com matrizes de raças lanígeras aumentou o peso final dos animais cruzados com a raça Ideal.

$\mathrm{O}$ peso ao desmame dos cordeiros da raça Ideal e Corriedale encontrados neste estudo são bastante próximos dos obtidos por RODA et al. (1984), para cordeiros criados em pastagem. Os ganhos de peso vivo encontrados para os animais cruzados são superiores aos de CARVALHO et al. (1997), para crias mestiças Ideal x Texel, confinadas e alimentadas com silagem de milho e concentrado, e aos de MACEDO et al. (1997) para cordeiros Corriedale ou 
246

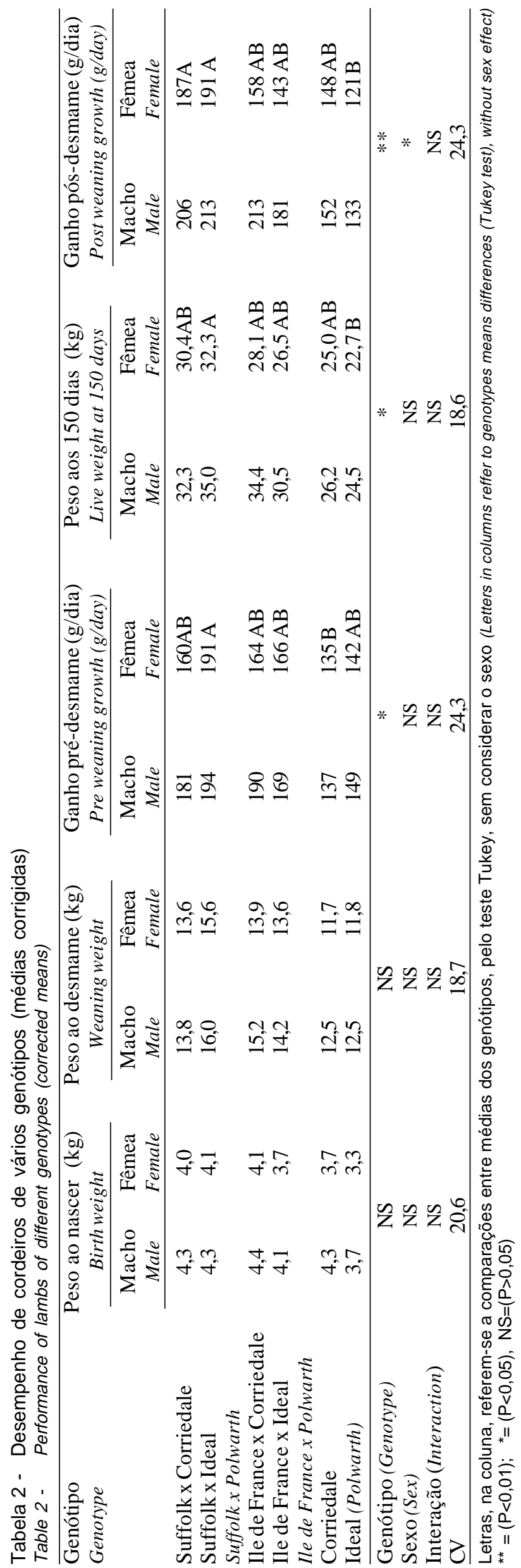

CUNHA et al.

cruzas desses com Bergamacia ou Hampshire. GUERRA e HERNANDEZ (1992) mostraram que o uso de machos de raça de corte (Suffolk ou Hampshire) sobre fêmeas lanígeras (Rambouilet) foi capaz de aumentar o peso ao abate de crias cruzados em relação aos puros.

A Tabela 3 apresenta o peso de abate dos cordeiros e os pesos e rendimentos de carcaça. Os pesos das carcaças quentes ou frias foram superiores para os animais cruzados em relação aos de raça pura lanígera e o do cruzamento da raça Suffolk x Ideal foi superior $(\mathrm{P}<0,01)$ aos demais, seguido pelos animais oriundos do genótipo Suffolk x Corriedale, Ile de France x Corriedale e Ile de France x Ideal, com as raças puras lanígeras apresentando os menores valores. Estes resultados indicaram que o uso de machos de corte sobre fêmeas lanígeras foi efetivo em aumentar o peso das carcaças, destacando-se o uso de machos Suffolk. A raça Ile de France também aumentou o peso das carcaças, podendo ser utilizada em tais cruzamentos.

Estes resultados concordam com os de CASOLI et al. (1984), que, na Itália, também conseguiram maior peso de carcaça de crias provenientes de cruzamentos de machos Suffolk ou Ile de France sobre fêmeas de raça Apenina (nativa) em relação aos animais puros Apeninos, e GÜNEY (1990), com o uso de carneiros Ile de France sobre ovelhas nativas. Contudo, MUNIZ et al. (1997) não obtiveram aumento no peso de carcaça fria de crias provenientes do cruzamento de Ile de France com Corriedale.

Os rendimentos de carcaça quente e fria apresentaram diferença $(\mathrm{P}<0,01)$ entre os genótipos avaliados. Os cordeiros da raça Corriedale apresentaram menor rendimento que os animais dos genótipos Suffolk x Ideal e Ile de France x Corriedale; os demais não apresentaram diferenças. Isso mostra que a raça Ile de France pode melhorar o rendimento de carcaça fria de cordeiros filhos de ovelhas Corriedale.

Os rendimentos de carcaça quente e fria foram similares aos encontrados por CARVALHO et al. (1997), para cordeiros confinados e abatidas com 137,3 dias, e MACEDO et al. (1997), para cordeiros confinados e abatidas aos 268 dias. Aumento do rendimento de carcaça de crias oriundas do uso de machos de corte sobre fêmeas não-especializadas foi constatado por MUNIZ et al. (1997) e GÜNEY (1990).

$\mathrm{O}$ peso das meias-carcaças e os percentuais de dianteiro, traseiro, costilhar, a espessura de gordura subcutânea e a área de olho de lombo podem ser visualizados na Tabela 4 . O rendimento dos cortes 
Tabela 3 - Peso de abate dos cordeiros e de suas carcaças (em $\mathrm{kg}$ ) e rendimento quente e frio (\% do peso de abate) (médias corrigidas) Table 3 - Slaughter and carcass weight $(\mathrm{kg})$ and hot and cold carcass dressing percentage (\% of slaughter weight) (corrected means)

\begin{tabular}{|c|c|c|c|c|c|c|c|c|c|c|}
\hline \multirow[t]{2}{*}{$\begin{array}{l}\text { Genótipo } \\
\text { Genotype }\end{array}$} & \multicolumn{2}{|c|}{$\begin{array}{l}\text { Peso ao abate } \\
\text { Slaughterweight }\end{array}$} & \multicolumn{2}{|c|}{$\begin{array}{c}\text { Peso carcaça quente } \\
\text { Hot carcass weight }\end{array}$} & \multicolumn{2}{|c|}{$\begin{array}{l}\text { Peso carcaça fria } \\
\text { Cold carcass weight }\end{array}$} & \multicolumn{2}{|c|}{$\begin{array}{l}\text { Rend. carcaça quente } \\
\text { Warm carcass dressing }\end{array}$} & \multicolumn{2}{|c|}{$\begin{array}{l}\text { Rend. carcaça fria } \\
\text { Cold carcass dressing }\end{array}$} \\
\hline & $\begin{array}{l}\text { Macho } \\
\text { Male }\end{array}$ & $\begin{array}{l}\text { Fêmea } \\
\text { Female }\end{array}$ & $\begin{array}{l}\text { Macho } \\
\text { Male }\end{array}$ & $\begin{array}{l}\text { Fêmea } \\
\text { Female }\end{array}$ & $\begin{array}{l}\text { Macho } \\
\text { Male }\end{array}$ & $\begin{array}{l}\text { Fêmea } \\
\text { Female }\end{array}$ & $\begin{array}{l}\text { Macho } \\
\text { Male }\end{array}$ & $\begin{array}{l}\text { Fêmea } \\
\text { Female }\end{array}$ & $\begin{array}{l}\text { Macho } \\
\text { Male }\end{array}$ & $\begin{array}{l}\text { Fêmea } \\
\text { Female }\end{array}$ \\
\hline Suffolk x Corriedale & 31,8 & 28,7 & 13,4 & $12,5 \mathrm{~B}$ & 12,8 & $11,9 \mathrm{~B}$ & 42,1 & $43,5 \mathrm{AB}$ & 40,1 & $41,3 \mathrm{AB}$ \\
\hline $\begin{array}{l}\text { Suffolk x Ideal } \\
\text { Suffolk x Polwarth }\end{array}$ & 32,5 & 31,1 & 14,3 & $13,8 \mathrm{~A}$ & 13,7 & $13,1 \mathrm{~A}$ & 44,0 & $44,1 \mathrm{~A}$ & 42,0 & $42,1 \mathrm{~A}$ \\
\hline Ile de France x Corriedale & 31,7 & 25,8 & 14,3 & $11,5 \mathrm{BC}$ & 13,6 & $11,0 \mathrm{BC}$ & 45,1 & $44,5 \mathrm{~A}$ & 42,9 & $42,4 \mathrm{~A}$ \\
\hline $\begin{array}{l}\text { Ile de France } \mathrm{x} \text { Ideal } \\
\text { Ile de France } x \text { Polwarth }\end{array}$ & 29,4 & 25,0 & 13,1 & $10,8 \mathrm{C}$ & 12,4 & $10,3 \mathrm{C}$ & 44,3 & $43,1 \mathrm{AB}$ & 42,2 & $40,9 \mathrm{~A}$ \\
\hline $\begin{array}{l}\text { Corriedale } \\
\text { Ideal } \\
\text { Polwarth } \\
\end{array}$ & $\begin{array}{l}25,4 \\
24,3\end{array}$ & $\begin{array}{l}24,1 \\
22,4\end{array}$ & $\begin{array}{l}10,5 \\
10,6\end{array}$ & $\begin{array}{l}10,1 \mathrm{D} \\
9,9 \mathrm{D}\end{array}$ & $\begin{array}{c}9,9 \\
10,0\end{array}$ & $\begin{array}{l}9,5 \mathrm{D} \\
9,4 \mathrm{D}\end{array}$ & $\begin{array}{l}41,1 \\
43,3\end{array}$ & $\begin{array}{l}41,9 \mathrm{~B} \\
44,2 \mathrm{AB}\end{array}$ & $\begin{array}{l}39,1 \\
41,0\end{array}$ & $\begin{array}{l}39,3 \mathrm{~B} \\
41,8 \mathrm{AB}\end{array}$ \\
\hline $\begin{array}{l}\text { Genótipo } \\
\text { Genotype }\end{array}$ & \multicolumn{2}{|c|}{-} & \multicolumn{2}{|c|}{$*$} & \multicolumn{2}{|c|}{$*$} & \multicolumn{2}{|c|}{$* *$} & \multicolumn{2}{|c|}{$* *$} \\
\hline $\begin{array}{l}\text { Sexo } \\
\text { Sex }\end{array}$ & \multicolumn{2}{|c|}{-} & \multicolumn{2}{|c|}{ NS } & \multicolumn{2}{|c|}{ NS } & \multicolumn{2}{|c|}{ NS } & \multicolumn{2}{|c|}{ NS } \\
\hline $\begin{array}{l}\text { Interação } \\
\text { Interaction }\end{array}$ & \multicolumn{2}{|c|}{-} & \multicolumn{2}{|c|}{ NS } & \multicolumn{2}{|c|}{ NS } & \multicolumn{2}{|c|}{ NS } & \multicolumn{2}{|c|}{ NS } \\
\hline $\begin{array}{l}\text { CV } \\
\text { Peso de abate (Covariável) } \\
\text { Slaughter weight (Covariate) }\end{array}$ & \multicolumn{2}{|c|}{-} & \multicolumn{2}{|c|}{$* *$} & \multicolumn{2}{|c|}{$* *$} & \multicolumn{2}{|c|}{$* *$} & \multicolumn{2}{|c|}{$* *$} \\
\hline
\end{tabular}

Letras nas colunas referem-se a comparações entre médias dos genótipos, pelo teste Tukey, sem considerar o sexo.

Letters in the columns reffer to genotypes means differences (Tukey test), without sex effect.

${ }^{* *}=(P<0,01) ;{ }^{*}=(P<0,05) ; N S=(P>0,05)$. 


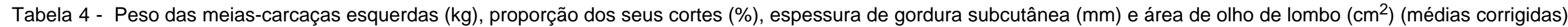
Table 4 - Left half carcasses weights $(\mathrm{kg})$, cuts ratio $(\%)$, subcutaneous fat thickness $(\mathrm{mm})$ and loin eye area $\left(\mathrm{cm}^{2}\right)(\mathrm{corrected} \mathrm{means)}$

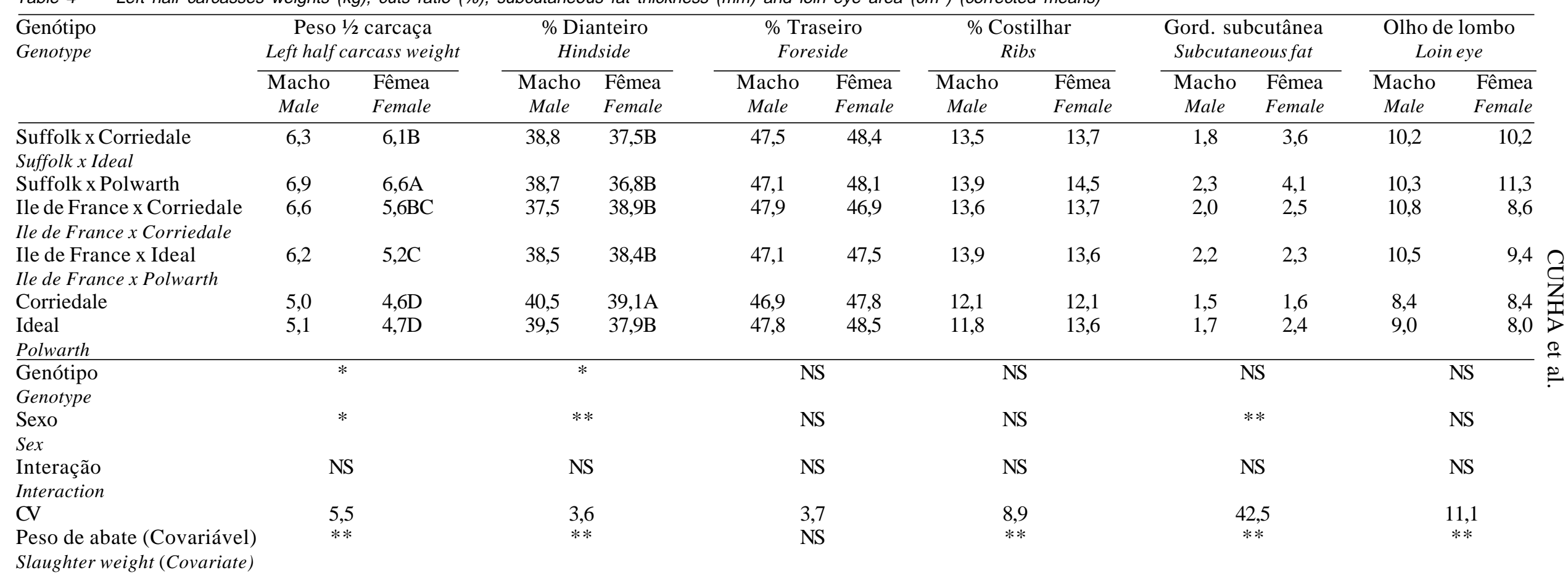

Letras nas colunas referem-se a comparações entre médias dos genótipos, pelo teste Tukey, sem considerar o sexo.

Letters in the columns reffer to genotypes means differences (Tukey test), without sex effect.

${ }^{* *}=(\mathrm{P}<0,01) ;{ }^{*}=(\mathrm{P}<0,05), \mathrm{NS}=(\mathrm{P}>0,05)$ 
apresentou diferença $(\mathrm{P}<0,05)$ apenas para a porcentagem de dianteiro, maior nos cordeiros Corriedale em relação aos demais. Foi averiguada, também, diferença $(\mathrm{P}<0,05)$ entre sexos, mostrando que os machos apresentam esta região anatômica mais desenvolvida que as fêmeas, provavelmente decorrente de dimorfismo sexual. Os demais cortes não apresentaram diferença, mostrando que todos os genótipos avaliados apresentam similaridades no corte mais nobre da carcaça, o traseiro.

A espessura de gordura subcutânea não mostrou diferenças entre genótipos $(\mathrm{P}>0,05)$, sendo, todavia, maior para as fêmeas $(\mathrm{P}<0,01)$. Isso mostra que as fêmeas depositam gordura na carcaça mais precocemente que os machos (BASS et al., 1990; MERSMANN, 1990), devido, provavelmente, às diferenças hormonais existentes entre os sexos. Constata-se que, quando se deseja mesma cobertura de gordura subcutânea, o peso de abate de fêmeas deve ser inferior aos dos machos.

Essa característica parece ser mais influenciada pelo peso de abate que pelo genótipo (WOOD et al. 1980), o que pode ser confirmado pela correlação positiva entre o peso de abate e a espessura de gordura $(r=0,67$ para macho e $r=0,74$ para fêmea). $O$ aumento do peso vivo ou grau de maturidade dos animais leva a aumento na proporção de gordura na carcaça, segundo SAINZ (1996). A espessura de gordura acima do músculo longissimus dorsi, segundo WOOD e MACFIE (1980), apresenta correlação com o peso total de gordura da carcaça. Isso mostra que animais mais pesados, ou seja, com maior grau de maturidade, apresentam maior espessura de gordura subcutânea que os animais mais leves, sendo fator importante para se definir a característica do produto a ser colocado no mercado.

Os valores de espessura de gordura subcutânea são muito inferiores ao citado por SAINZ (1996), como máximo desejável nos Estados Unidos, inferiores aos de BONA FILHO et al. (1994), para cordeiros mestiços abatidos com 139 dias de idade e peso ao redor de $40 \mathrm{~kg}$, e superiores aos de MACEDO et al. (1997), para crias cruzadas abatidas ao redor de 270 dias.

A área de olho de lombo (AOL) não mostrou diferença para genótipos e sexo. Este fato concorda com FAHMY (1985), que também não encontrou diferenças na AOL entre cordeiros de vários cruzamentos abatidos com peso vivo semelhantes. Todavia, mostrou correlação positiva com o peso ao abate $(\mathrm{r}=0,87)$, mostrando que este, e não o genótipo, é fator determinante dessa variável. JONES et al. (1996) também mostraram que a AOL é influenciada pelo peso da carcaça quente.

Os valores para AOL encontrados para os animais cruzados são superiores aos de PIRES et al. (1996), para crias mestiças abatidas ao redor de $30 \mathrm{~kg}$. ARAUJO et al. (1996) encontraram, para crias Ideal com peso de carcaça de $11,5 \mathrm{~kg}$, valores levemente inferiores aos das crias Ideal deste estudo. MACEDO et al. (1997) encontraram valor de AOL similar ao deste estudo para cordeiros cruzados abatidos entre 30 e $32 \mathrm{~kg}$ de peso vivo. CARVALHO et al. (1997) obtiveram valor de AOL inferior ao deste estudo, para crias abatidas com $20,7 \mathrm{~kg}$.

O comprimento interno e externo da carcaça, a profundidade de tórax e o comprimento e perímetro da perna são apresentadas na Tabela 5. O comprimento externo das carcaças apresentou diferença estatística entre genótipos $(\mathrm{P}<0,05)$, e não entre sexos. Os cordeiros oriundos do cruzamento com Suffolk mostraram carcaças mais compridas e os animais puros da raça Ideal, carcaças mais curtas; os cruzados da raça Ile de France ou Corriedale puro apresentaram valores intermediários.

O comprimento interno apresentou valores maiores $(\mathrm{P}<0,01)$ para os cruzados Suffolk, seguidos pelos cruzados Ile de France; as raças puras apresentaram os menores valores.

A profundidade do tórax foi maior para os cruzados com Suffolk em relação aos Corriedales puros. O comprimento da perna foi maior para os animais Suffolk x Ideal e inferior para os cordeiros puros da raça Ideal, sendo os demais genótipos em posição intermediária. O perímetro da perna mostrou valores superiores $(\mathrm{P}<0,05)$ para os cruzados Suffolk e valores inferiores para os animais da raça Corriedale puros. Não foi observada diferença entre sexos para estas variáveis.

As correlações entre as medidas das carcaças e os pesos vivos ao abate e pesos das carcaças foram altamente significativas (Tabela 6), mostrando que estas podem ser utilizadas para inferir o peso das carcaças; dentre estas, a profundidade do tórax foi a que apresentou maior valor de coeficiente de correlação $(r=0,88)$ com os pesos de carcaça quente e fria. Este fato concorda com EL KARIN et al. (1988), ao afirmarem que esta medida apresenta o maior coeficiente de correlação com o peso de carcaça.

Na Tabela 7, é apresentada a relação entre o perímetro e comprimento da perna e o índice de compacidade da carcaça (peso da carcaça fria/com- 
Tabela 5 - Medidas de carcaça $(\mathrm{cm})$ de cordeiros de vários genótipos (médias corrigidas)

Table 5 - Carcass measurements (cm) of lambs of different genotypes (corrected means)

\begin{tabular}{|c|c|c|c|c|c|c|c|c|c|c|}
\hline \multirow[t]{2}{*}{$\begin{array}{l}\text { Genótipo } \\
\text { Genotype }\end{array}$} & \multicolumn{2}{|c|}{$\begin{array}{c}\text { Comprimento externo } \\
\text { External lenght }\end{array}$} & \multicolumn{2}{|c|}{$\begin{array}{c}\text { Comprimento interno } \\
\text { Internal lenght }\end{array}$} & \multicolumn{2}{|c|}{$\begin{array}{c}\text { Profundidade torax } \\
\text { Chest depth } \\
\end{array}$} & \multicolumn{2}{|c|}{$\begin{array}{c}\text { Comprimento perna } \\
\text { Leg lenght }\end{array}$} & \multicolumn{2}{|c|}{$\begin{array}{c}\text { Perimetro perna } \\
\text { Leg perimeter }\end{array}$} \\
\hline & $\begin{array}{l}\text { Macho } \\
\text { Male }\end{array}$ & $\begin{array}{l}\text { Fêmea } \\
\text { Female }\end{array}$ & $\begin{array}{l}\text { Macho } \\
\text { Male }\end{array}$ & $\begin{array}{l}\text { Fêmea } \\
\text { Female }\end{array}$ & $\begin{array}{l}\text { Macho } \\
\text { Male }\end{array}$ & $\begin{array}{l}\text { Fêmea } \\
\text { Female }\end{array}$ & $\begin{array}{l}\text { Macho } \\
\text { Male }\end{array}$ & $\begin{array}{l}\text { Fêmea } \\
\text { Female }\end{array}$ & $\begin{array}{l}\text { Macho } \\
\text { Male }\end{array}$ & $\begin{array}{l}\text { Fêmea } \\
\text { Female }\end{array}$ \\
\hline Suffolk x Corriedale & 55,0 & $55,5 \mathrm{~A}$ & 53,2 & $54,0 \mathrm{~A}$ & 31,8 & $30,7 \mathrm{AB}$ & 37,4 & $36,4 \mathrm{AB}$ & 39,3 & $40,0 \mathrm{AB}$ \\
\hline $\begin{array}{l}\text { Suffolk x Ideal } \\
\text { Suffolk } x \text { Polwarth }\end{array}$ & 56,1 & $55,2 \mathrm{~A}$ & 55,9 & $54,7 \mathrm{~A}$ & 32,3 & $31,8 \mathrm{~A}$ & 37,8 & $37,7 \mathrm{~A}$ & 40,8 & $40,7 \mathrm{~A}$ \\
\hline Ile de France x Corriedale & 53,0 & $51,4 \mathrm{~B}$ & 48,0 & $49,7 \mathrm{~B}$ & 32,5 & $30,4 \mathrm{AB}$ & 35,8 & $35,1 \mathrm{BC}$ & 38,3 & $37,0 \mathrm{BC}$ \\
\hline $\begin{array}{l}\text { Ile de France } \mathrm{x} \text { Ideal } \\
\text { Ile de France } x \text { Polwarth }\end{array}$ & 52,2 & $49,2 \mathrm{BC}$ & 49,6 & $48,5 \mathrm{~B}$ & 31,5 & $29,8 \mathrm{ABC}$ & 35,5 & $34,8 \mathrm{BCD}$ & 39,7 & $38,1 \mathrm{AB}$ \\
\hline Corriedale & 51,3 & $47,8 \mathrm{BC}$ & 45,5 & $42,1 \mathrm{C}$ & 28,8 & $29,8 \mathrm{C}$ & 34,5 & $33,3 \mathrm{CD}$ & 34,5 & $33,1 \mathrm{D}$ \\
\hline $\begin{array}{l}\text { Ideal } \\
\text { Polwarth }\end{array}$ & 49,7 & $47,2 \mathrm{C}$ & 44,7 & $43,0 \mathrm{C}$ & 30,3 & $29,6 \mathrm{BC}$ & 33,0 & $33,4 \mathrm{D}$ & 36,0 & $34,2 \mathrm{CD}$ \\
\hline
\end{tabular}

Genotype

NS

NS

NS

NS

NS

Sex

Interação

Interaction

CV

NS

NS

NS

NS

NS

Peso de abate (covariável)

4,2

7,0

4,1

4,0

6,7

Letras nas colunas referem-se a comparações entre médias dos genótipos, pelo teste Tukey, sem considerar o sexo.

Letters in columns reffer to genotypes means differences (Tukey test), without sex effect.

${ }^{* *}=(P<0,01) ; \quad *=(P<0,05), N S=(P>0,05)$. 
primento externo). A relação entre o perímetro e o comprimento da perna não apresentou diferença significativa para genótipos e sexo, mostrando que os animais apresentaram desenvolvimento harmonioso entre estas. A relação entre o perímetro e o comprimento não apresentou correlação (Tabela 6) com qualquer outra variável estudada.

O índice de compacidade mostrou efeito significativo somente entre os genótipos $(\mathrm{P}<0,01)$, sendo maior para os animais cruzados Ile de France e menor para os puros lanígeros, com os cruzados Suffolk apresentando valores intermediários. A compacidade da carcaça apresentou correlação positiva e significativa com o peso de abate $(\mathrm{r}=0,94)$ e da carcaça quente $(\mathrm{r}=0,96)$ ou fria $(\mathrm{r}=0,96)$, mostrando que $\mathrm{o}$ peso de abate tem grande influência sobre esta variável. Apesar dos cruzados Suffolk apresentarem, em média, carcaças mais pesadas, em função do maior comprimento, verificou-se menor compacidade em relação aos cruzados Ile de France.

Tabela 6 - Correlações entre medidas e pesos das carcaças

Table 6 - Correlations between carcass measures and weights

\begin{tabular}{lccc}
\hline Item & $\begin{array}{c}\text { Peso ao abate } \\
\text { Slaughterweight }\end{array}$ & $\begin{array}{c}\text { Peso da carcaça quente } \\
\text { Hot carcass weight }\end{array}$ & $\begin{array}{c}\text { Peso da carcaça fria } \\
\text { Cold carcass weight }\end{array}$ \\
\hline $\begin{array}{l}\text { Comprimento externo } \\
\text { External lenght }\end{array}$ & $0,85^{* *}$ & $0,86^{* *}$ & $0,85^{* *}$ \\
$\begin{array}{l}\text { Comprimento interno } \\
\text { Internal lenght }\end{array}$ & $0,79^{* *}$ & $0,80^{* *}$ & $0,80^{* *}$ \\
$\begin{array}{l}\text { Profundidade do tórax } \\
\text { Chest depth }\end{array}$ & $0,87^{* *}$ & $0,88^{* *}$ & $0,88^{* *}$ \\
$\begin{array}{l}\text { Comprimento da perna } \\
\text { Leg length }\end{array}$ & $0,85^{* *}$ & $0,83^{* *}$ & $0,83^{* *}$ \\
$\begin{array}{l}\text { Perímetro da perna } \\
\text { Leg perimeter } \\
\text { Compacidade } \\
\text { Compacticity }\end{array}$ & $0,80^{* *}$ & $0,82^{* *}$ & $0,82^{* *}$ \\
$\begin{array}{l}\text { Perímetro/circunferência da perna } \\
\text { Leg perimeter/lenght }\end{array}$ & $0,33^{\mathrm{NS}}$ & $0,96^{* *}$ & $0,96^{* *}$ \\
$* *$ - (P<0,01) NS - (P>0,05) & $0,38^{\mathrm{NS}}$ & $0,39^{\mathrm{NS}}$ \\
\hline
\end{tabular}

Tabela 7 - Relação perímetro/comprimento da perna (pp/cp), índice de compacidade (peso da carcaça fria/comprimento externo) (médias corrigidas)

Table 7 - Leg perimeter and length ratio (Ip/ll), compacticity index (cold carcass weigh/carcass external lenght) (corrected means)

\begin{tabular}{|c|c|c|c|c|}
\hline \multirow[t]{2}{*}{$\begin{array}{l}\text { Genótipo } \\
\text { Genotype }\end{array}$} & \multicolumn{2}{|c|}{$\begin{array}{c}\text { Relação } \mathrm{Pp} / \mathrm{Cp} \\
\text { Lp/Ll ratio }\end{array}$} & \multicolumn{2}{|c|}{$\begin{array}{l}\text { Compacidade } \\
\text { Compacticity }\end{array}$} \\
\hline & $\begin{array}{l}\text { Macho } \\
\text { Male }\end{array}$ & $\begin{array}{l}\text { Fêmea } \\
\text { Female }\end{array}$ & $\begin{array}{l}\text { Macho } \\
\text { Male }\end{array}$ & $\begin{array}{l}\text { Fêmea } \\
\text { Female }\end{array}$ \\
\hline Suffolk x Corriedale & 1,05 & 1,10 & 0,24 & $0,22 \mathrm{~B}$ \\
\hline Suffolk x Ideal & 1,08 & 1,08 & 0,24 & $0,24 \mathrm{~B}$ \\
\hline Suffolk $x$ Polwarth & & & & \\
\hline Ile de France x Corriedale & 1,07 & 1,05 & 0,28 & $0,22 \mathrm{~A}$ \\
\hline Ile de France x Ideal & 1,12 & 1,09 & 0,25 & $0,21 \mathrm{AB}$ \\
\hline Ile de France $x$ Polwarth & & & & \\
\hline Corriedale & 1,00 & 0,99 & 0,21 & $0,23 \mathrm{C}$ \\
\hline Ideal & 1,09 & 1,02 & 0,22 & $0,22 \mathrm{C}$ \\
\hline Polwarth & & & & \\
\hline Genótipo(Genotype) & \multicolumn{2}{|c|}{ NS } & \multicolumn{2}{|c|}{$* *$} \\
\hline $\operatorname{Sexo}(\operatorname{Sex})$ & \multicolumn{2}{|c|}{ NS } & \multicolumn{2}{|c|}{ NS } \\
\hline Interação (Interaction) & \multicolumn{2}{|c|}{ NS } & \multicolumn{2}{|c|}{ NS } \\
\hline $\mathrm{CV}$ & \multicolumn{2}{|c|}{7,7} & \multicolumn{2}{|c|}{5,0} \\
\hline Peso de abate (Covariável) & \multirow{2}{*}{\multicolumn{2}{|c|}{$*$}} & \multirow{2}{*}{\multicolumn{2}{|c|}{$* *$}} \\
\hline Slaughter weight (Covariate) & & & & \\
\hline
\end{tabular}




\section{Conclusões}

A utilização de carneiros da raças Suffolk ou Ile de France, especializados para corte, sobre fêmeas lanígeras resulta em aumento no peso da carcaça de suas crias.

As raças Suffolk e a Ile de France apresentaram, respectivamente, aumento do comprimento e da compacidade da carcaça.

A espessura da gordura subcutânea é influenciada pelo sexo e pelo peso vivo ao abate, não havendo efeito do genótipo, ao passo que a área de olho de lombo é afetada somente pelo peso vivo ao abate.

As medidas de carcaça podem ser utilizadas para estimar o seu peso.

\section{Referências Bibliográficas}

ARAUJO, J.R., PIRES, C.C., FIGUEIRÓ, P.R.P. et al. Características da carcaça e composição física do quarto de crias abatidos à mesma maturidade In: REUNIÃO ANUAL DA SOCIEDADE BRASILEIRA DE ZOOTECNIA, 33, 1996, Fortaleza. Anais... Fortaleza: SBZ, 1996, v.3, p.156-158.

BASS, J.J., BUTLER-HOGG, B.W., KIRTON, A.H. 1990. Practical methods of controlling fatness in farm animals. In: WOOD, J.D., FISHER, A.V. (Eds.) Reducing fat in meat animals. London: Elsevier Science Publishers Ltda. p.145-200.

BONNA FILHO, A., OTTO, C., LEME, M.C.J. et al. 1994. Ganho de peso e características de carcaça de crias confinados e suplementados com diferentes níveis de farinha de peixe em substituição ao farelo de soja. R. Set. Ci. Agr., 13(1-2):183-191.

CARVALHO, S., PIRES, C.C., SACILOTTO, M.P. et al. Efeito de dois sistemas de alimentação sobre o desempenho e características da carcaça de crias alimentados ao pé da mãe. In: REUNIÃO ANUAL DA SOCIEDADE BRASILEIRA DE ZOOTECNIA, 34, 1997, Juiz de Fora, MG. Anais... Juiz de Fora: SBZ, 1997, v.1, p.376-378.

CASOLI, C., DURANTI, E., BIANCHI, R.F. et al. 1984. Prove di incrocio industriale su pecore di razza appenninica. Zoot. Nutr. Anim., 10(3):217-227.

EL KARIN, A.I.A., OWENS, J.B., WHITAKER, C.J. 1988. Measurement on slaughter weight, side weight, carcass joints and their association with composition of two types of sudan desert sheep. J. Agric. Sci., 110(1):65-69.

FAHMY, M.H. 1985. The acumulative effect of finnsheep breeding in crossbreeding schemes: growth and carcass traits. Can. J. Anim. Sci., 65(3):811-819.

FERNANDES, S. Peso vivo ao abate e características de carcaça de cordeiros da raça Corriedale e mestiços Ile de France $x$ Corriedale, recriados em confinamento. Botucatu, SP: Faculdade de Medicina Veterinária e Zootecnia, 1994. 82p. Dissertação (Mestrado em Zootecnia) -Universidade Estadual Paulista, 1994.

GUERRA, J.O.S., HERNÁNDEZ, G.T. 1992. Aumento de peso en corderos de ovejas Rambouillet apareadas con sementales Suffolk, Hampshire y Rambouillet en el altiplano Potosino. Vet. Mex., 23(3):234-247.
GÜNEY, O. 1990. Commercial corssbreeding between Ile de France, Rambouillet, Chios and local fat-tail Awassi for market lamb production. Small Ruminant Research, $3(5): 449-456$.

JONES, S.D.M., ROBERTSON, W.M., PRICE, M.A. et al. 1996. The prediction of saleable meat yield in lamb carcasses. Can. J. Anim. Sci., 76(1):49-53.

MACEDO, F.A.F., MARTINS, E.N., SIQUEIRA, E.R. et al. Cruzamentos e sistemas de terminação na produção de carcaças de crias. In: REUNIÃO ANUAL DA SOCIEDADE BRASILEIRA DE ZOOTECNIA, 34, 1997, Juiz de Fora. Anais... Juiz de Fora: SBZ, 1997, v.1, p.388-390.

MERSMANN, H.J. 1990. Metabolic and endocrine control of adipose tissue accretion. In: WOOD, J.D., FISHER, A.V. (Eds.). Reducing fat in meat animals. London: Elsevier Science Publishers Ltda. p.101-144.

MUNIZ, E.N.M., PIRES, C.C., SILVA, J.H.S. et al. Crescimento ponderal e características da carcaça de cordeiros de diferentes genótipos. In: REUNIÃO ANUAL DA SOCIEDADE BRASILEIRA DE ZOOTECNIA, 34, 1997, Juiz de Fora, MG. Anais... Juiz de Fora: SBZ, 1997, v.3, p.293-295.

PIRES, C.C., ROSA, G.T., GONÇALVES, J. et al. Desempenho e características de carcaça de crias terminados em confinamento. In: REUNIÃO ANUAL DA SOCIEDADE BRASILEIRA DE ZOOTECNIA, 33, Fortaleza, 1996 Anais... Fortaleza: SBZ, 1996, v.3, p.513-515.

RODA, D.S., SANTOS, L.E., CUNHA, E.A. et al. 1993. Desempenho de ovinos em sistema de acasalamento a cada oito meses. Bol. Ind. Anim., 50(1):49-54.

RODA, D.S., SANTOS, L.E., OLIVEIRA, A.A.D. 1984. Desempenho de crias submetidos a diferentes períodos de aleitamento e suplementação alimentar. Bol. Ind. Anim., 41(único):85-101.

RODA, D.S., SANTOS, L.E., OLIVEIRA, A.A.D. et al. 1983. Crescimento ponderal de cordeiros deslanados Suffolk e cruzados deslanados x Suffolk. Bol. Ind. Anim., 40(1):25-30.

SAINZ, R. Qualidade das carcaças e de carne ovina e caprina. In: REUNIÃO ANUAL DA SOCIEDADE BRASILEIRA DE ZOOTECNIA, 33, Fortaleza, 1996. Anais... Fortaleza: SBZ, 1996, p.3-14.

WOOD, J.D., MACFIE, H.J.H. 1980. The significance of breed in the prediction of lamb carcass composition from fat thickness measurements. Anim. Prod., 31(3):315-319.

WOOD, J.D., MACFIE, H.J.H., POMERY, R.W. et al. 1980. Carcass composition in four sheep breeds: the importance of breed and stage of maturity. Anim. Prod., 30(1):135-152.

Recebido em: 11/03/98 Aceito em: 16/08/99 